DOI: http://dx.doi.org/10.22201/iie.18703062e.2000.77.1943

\author{
ALBERTO PÉREZ-AM ADOR ADAM \\ UNIVERSITÄT WUPPERTAL
}

\title{
El triunfo del demiurgo
}

\section{Acerca de Muartesin fin de José G orostiza}

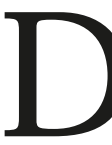

ESPUÉS DE VARIAS RESEÑAS positivas de sus primeros poemas, reunidos bajo el título Canciones para cantar en las barcas, la crítica especializada no se volvió a ocupar de Gorostiza. Pero en 1939, con la publicación de su obra mayor, el poema Muerte sin fin, su actividad creativa llamó nuevamente la atención. Su amigo Jorge Cuesta escribió, en el lapso de pocas semanas, dos reseñas de la obra. ${ }^{.}$Esto no es coincidencia: G orostiza y Cuesta, poetas con concepciones estéticas similares, eran amigos desde hacía diez años, conocían sus respectivos proyectos, y se influyeron mutuamente al redactar, en forma simultánea, sus poemas mayores, M uerte sin fin y Canto a un dios mineral. Cuesta subraya la importancia de la metáfora principal de la obra, la del vaso de agua, y la interpreta como "[... ] los amores de la forma y de la materia, o como los amores del cuerpo y del espíritu, o como los amores de la parte sensible y de la parte inteligible de la conciencia".

En la segunda reseña, Cuesta subraya el carácter místico del poema, relacionándolo con la obra de André Gide y T. S. Eliot, para después establecer una larga comparación con el Cántico espiritual de san Juan de la C ruz. Esto es doblemente interesante, pues la crítica posterior tan sólo ha reparado en las características formales inmediatas de la obra para inscribirla, superficialmente, como continuación de una tradición poética representada por Le ci-

I. Poemas y ensayos III (Ensayos 2), M éxico, U niversidad N acional Autónoma de M éxico, 1964, pp. 326-331, 363-367. La primera reseña se publicó el I8 de diciembre de 1939 en N oticias Gráficas y la segunda el is de febrero de 1940 en Romance. 
DOI: http://dx.doi.org/10.22201/iie.18703062e.2000.77.1943

190

ALBERTO PÉREZ-AMADOR ADAM

metière marin (1920) de P. Valéry, The Waste Land (1922) de T. S. Eliot y Anabase (1927) de Saint John Perse. Pero, en realidad, M uerte sin fin, como lo había declarado Cuesta, además de relacionarse con dichos autores, continúa una centenaria tradición hispana de poemas filosóficos largos que va desde las Coplas de Jorge M anrique y la segunda Égloga de Garcilaso de la Vega, pasando por el Cántico espiritual de san Juan de la C ruz y las Soledades de Góngora, hasta renovarse poco antes de Gorostiza en el siglo Xx. ${ }^{2}$

En 1927 los poetas jóvenes españoles honraron el tercer centenario luctuoso de Luis de Góngora declarándose continuadores de la tradición poética iniciada por él. Lo correspondiente hicieron los poetas mexicanos del grupo Contemporáneos al reeditar la obra de sor Juana Inés de la Cruz. Gorostiza, Cuesta y Villaurrutia editaron sus sonetos, endechas y su Primero sueño, que es su particular aportación a la tradición hispana del poema filosófico.

Si bien no ha habido crítico que niegue la influencia de sor Juana en la poesía de los Contemporáneos, tampoco ha habido estudios dedicados al tema. Al respecto es de particular importancia el ensayo de Jorge Cuesta, El dasicismo mexicano. ${ }^{3}$ El origen de su redacción se encuentra en el intento de defender a los poetas del grupo C ontemporáneos por no dedicarse a la literatura comprometida socialmente. Esta discusión se dio al debatirse la función y carácter nacionalista de la literatura posrevolucionaria ante los triunfos internacionales obtenidos por la pintura muralista mexicana y las obras sinfónicas de la escuela nacionalista musical. En tal ensayo, al justificar la obra del grupo, Cuesta establece la tradición de la poesía mexicana que los C ontemporáneos intentan continuar. Su argumentación inicia estableciendo el carácter de la lengua como producto transplantado a tierras ajenas en el momento que algunos de los valores más altos de 0 ccidente se expresaban a través de ella. Las obras entonces redactadas en M éxico y el resto de $\mathrm{H}$ ispanoamérica surgieron bajo las condiciones históricas únicas de emplear una lengua que ha alcanzado su máxima capacidad expresiva, pero que es nueva en aquella geografía. Al mismo tiempo, estas obras participaban de la tradición humanista surgida de Erasmo y que tuvo en el mundo hispano singulares conse-

2. Al respecto debe mencionarse Altazor (193I) de Vicente $\mathrm{H}$ uidobro, M uerte de $\mathrm{N}$ arciso (1937) de J osé Lezama Lima y EI diluvio de fuego (1938) de Enrique G onzález M artínez.

3. Publicado primeramente en El libro y el pueblo, agosto de 1934, pp. 367-378 y reeditado en Poemas y ensayos I, M éxico, U niversidad N acional Autónoma de M éxico, 1964, pp. I78-I94. 
cuencias. ${ }^{4}$ Cuesta afirma que tal tradición humanista continuó cultivándose en los siguientes siglos hasta enfrentarse, en el siglo XIX, al movimiento nacionalista. Su argumentación gira alrededor de la dicotomía "clásico-universal" vs. "no clásico-nacional" para mostrar las limitaciones regionalistas de la mayoría de las literaturas nacionales europeas surgidas en los últimos doscientos años. Así logra develar una severa tradición en la poesía mexicana que desde sus inicios renacentistas hasta la actual idad ha difundido los valores comunes a toda la cultura occidental. Las obras de Bernardo de Balbuena (1564-1627), Juan Ruiz de Alarcón (1580-1639), Luis de Sandoval Zapata (I620-167I), Carlos Sigüenza y Góngora (I645-1700) y sor Juana Inés de la Cruz (1648-1695), entre otros, son no sólo el ápice de una tradición mexicana, sino ejemplos singulares de la literatura hispanoamericana. Finalmente, Cuesta reconoce en aquella poesía que evita el regionalismo, aspirando a los más al tos ideales humanistas, la única capaz de expresar los valores de un clasicismo mexicano-latinoamericano.

Sus ideas explican el interés de los Contemporáneos por la obra de sor Juana y la influencia de su obra: su Primero sueño, distanciado por su contenido filosófico de los superficiales juegos formales de G óngora, es para los C ontemporáneos el ejemplo de poesía exigente eximida de todo regionalismo, capaz de fundar una tradición poética. Tales ideas han influido desde entonces la literatura mexicana, en particular la redacción de poemas filosóficos largos, desde los Contemporáneos, pasando por 0 ctavio Paz y Rubén Bonifaz N uño, hasta David H uerta. La obra de estos poetas tiene puntos comunes en su aspiración filosófica. Su atención se concentra en problemas ontológicos usuales como la búsqueda de D ios, el origen del universo, la capacidad intelectiva entendida como sinécdoque del ser humano, y el lenguaje poético como instrumento de la crítica en el proceso cognoscitivo de una modernidad reconocida en su fracaso.

M uchas fuentes han sido localizadas para explicar M uerte sin fin. En la construcción de las metáforas se observan analogías con el Antiguo Testamento. Del libro de la Sabiduría proceden los conceptos de D ios y del D iablo, de la vida y la muerte, del espejo y la luz, la idolatría, la inteligencia y la creación; del Eclesiástico aquellas ideas del sueño como mentira y reflejo (34, I-8). 0 tras fuentes se localizan en los Proverbios de Salomón, los Salmos de D avid y el Génesis. Por otra parte, la Cábala y, en particular, el Sefer ha-Zohar (Libro

4. Cfr. M arcel Bataillon, Erasmo y España. Estudios sobre la historia espiritual del siglo Xvı, M éxico-M adrid, Fondo de Cultura E conómica, 1986. 
DOI: http://dx.doi.org/10.22201/iie.18703062e.2000.77.1943

192

ALBERTO PÉREZ-AMADOR ADAM

del resplandor) y el Sefer Yetzirá (Libro de la creación) sirvieron de fuente filosófica. La influencia del Sefer Yetzirá no se reduce sólo a los motivos de la creación y la descreación - entendiéndose por ello la paulatina involución de la creación- localizables en las partes tercera y novena de M uerte sin fin, sino también en la común estructuración en diez partes. Tal estructura es ejemplo de un extraordinario ejercicio de abstracción y capacidad compositiva poética. La obra se divide en diez partes, de diversa extensión, no numeradas y divididas, a su vez, en dos grandes secciones. Tales comprenden las partes primera a cuarta y de la sexta a la novena, y están compuestas según las reglas dictadas por la silva, es decir hepta y endecasílabos de rima libre. Ambas partes terminan con el mismo verso de referencia bíblica (iAleluya! ¡Aleluya!) y están estructuradas en forma inversa: la parte primera introduce los temas a desarrollar en las siguientes tres, mientras en la segunda sección las partes sexta a octava son resumidas en la novena. La parte quinta y décima están compuestas, la primera de ellas, según los dictados formales de la seguidilla, es decir, hepta y pentasílabos, y la segunda según los del romance, es decir, octosílabos en estrofas regulares. En estas dos partes se emplean locuciones provenientes de un proverbio y de una ronda infantil respectivamente ("ahogarse en un vaso de agua" y "iTan-Tan! ¿Q uién es? Es el D iablo"). Ambas partes terminan con un refrán, denominado en el texto, entre corchetes, como [Baile], y el cual inicia en forma jovial para finalizar trágicamente. Por su fondo y estructura hay similitudes entre las partes primera y sexta, segunda y séptima, quinta y décima. En las partes centrales se observa una estructuración en cruz donde la parte tercera mantiene una relación con la novena y la cuarta con la octava. Al estudiarse la obra de manera más detenida se descubre que los principios numerológicos determinan la estructuración interna de algunas partes. Así, por ejemplo, los siete incisos constituyentes de la novena parte, donde se describe el proceso involutivo de la naturaleza, reflejan el número de días necesitados por el dios bíblico para completar su creación.

Para obtener la unidad interna de las diferentes partes se repiten, en forma completa o fragmentaria, algunos versos. La obra está construida con base en cuatro isotopías cuyos campos semánticos se entrecruzan. La primera

5. El concepto de isotopía se emplea aquí en el sentido de campo semántico, es decir de una serie de imágenes desarrolladas a lo largo de varios versos, tal como A. J. G reimas definió el concepto (Sémiotique. D ictionnaire raisonné de la théorie du langage, París, H achette U niversité, 1979). 
se constituye de la tricotomía forma-vaso-dios que forma parejas con los elementos de la segunda, que contiene los conceptos sustancia-agua-alma. Las dos restantes isotopías se constituyen de diferentes conceptos que, si bien son sutilmente entrelazados, en realidad forman oposiciones entre sí. En la primera se localizan los conceptos muerteinversión (descreación)-oscuridadprecipicio-diablo-inmovilidad-silencio, mientras en la segunda se encuentra la idea de sueño-creación-luz-altura-sentidos corporales-movimiento-palabra. ${ }^{6}$

El motivo central del poema que permite el entrecruzamiento de estas cuatro isotopías lo constituye el motivo de la inteligencia. Esto se presenta con claridad en la cuarta parte del poema dedicada a este motivo, desarrollado a partir de dos conceptos diferentes: la inteligencia divina y la inteligencia humana. En el pensamiento gnóstico, que determina todo el poema, se presupone una diferenciación en el ser de Dios: se identifica una inteligencia divina que concibe las ideas:

¡OH INTELIGENCIA, soledad en llamas, que todo lo concibe sin crearlo! $(\mathrm{IV}, \mathrm{I}-2)$

pero que no realiza tales conceptos, puesto que para ello existe otra potencia que

[... ] le infunde el soplo que lo pone en pie

$(\operatorname{IV}, 9)$

Tal escisión es identificable en los epígrafes introductorios a la obra provenientes del libro de los Proverbios $(8,30)$. Estos difíciles versos hallan explicación en el Sefer ha-Zohar : la Cábala distingue entre D ios y la Shejiná, esto es, respectivamente, una inteligencia divina que concibe ideas, y una sapiencia creadora de las formas. ${ }^{7}$ Se identifica a D ios con la fuerza genésica, siendo Él quien concibe las ideas realizadas por la sapiencia creadora de las formas conocida como Shejiná. Los gnósticos desarrollaron estas ideas: no sólo reconocían dos entidades diferentes en el ser de dios, sino aun dos fuerzas dife-

6. Beatriz Garza Cuarón, "Simetría y correspondencias en M uerte sin fin de José G orostiza", en varios, D esindes literarios, M éxico, El Colegio de M éxico, I977, pp. 83-94.

7. Cfr. J. Lacarrière, Los gnósticos, M éxico, La Red de Jonás, 1982. 
DOI: http://dx.doi.org/10.22201/iie.18703062e.2000.77.1943

194

ALBERTO PÉREZ-AMADOR ADAM

rentes. La primera siempre se designó como dios, mientras la segunda, de pendiendo de la secta gnóstica, se llamó desde Sofía hasta D emiurgo. D ios fue concebido como una unidad, como el amorfo continuo, que concibe las ideas. El demiurgo era una fuerza surgida de aquel amorfo continuo que realiza las ideas concebidas gracias a la intervención de la forma y por medio de la infinita división de Dios, es decir, del amorfo continuo. La existencia del mal y la imperfección en el mundo se explica a partir del hecho de no ser Dios, sino sólo el $D$ emiurgo el autor de la creación. La única manera de restituir la unidad divina y dar término a las imperfecciones sería la interrupción e inversión de la obra del demiurgo, es decir, de la creación de la materia a partir de la división de D ios. La humanidad, en consecuencia, está en un error al adorar al Dios creador, quien, en realidad, es el origen del mal, mientras que considera como maligno al que pretende desleír la creación para regresar a la original unidad divina.

Tal como los gnósticos, G orostiza también reconoce tal escisión en el ser humano, distinguiendo entre la inteligencia que concibe y aquella otra que, a manera del dios bíblico, crea por medio de la palabra un mundo (poético). Tal idea lo conduce al problema principal de su poema M uerte sin fin: el problema de forma y sustancia tanto en la creación divina (entiéndase del demiurgo) surgida del Verbo divino, como también en aquella creación humana constituida de palabras, es decir, la poesía. Para responder la pregunta correspondiente a forma y sustancia, G orostiza regresa a la lección del proceso creativo propuesta en el Sefer ha-Zohar. En oposición a la interpretación cristiana (paulina), que concibe a Dios como sustancia y al hombre como forma, en el Sefer ha-Zohar se invierte tal proposición: D ios, todo sustancia, crea la forma abstracta, que inicia el proceso de diferenciación de la sustancia del amorfo continuo, es decir, de Dios mismo, luego de que Él intentó, vanamente, la creación de manera sustancial. ${ }^{8}$ Así se distingue al Dios como sustancia unitaria original del $\mathrm{D}$ ios creador de la forma y ordenador de la sustancia. La forma abstracta es considerada, en el Sefer ha-Zohar, como origen

8. Explica Jean M arquès-Rivière: "Dieu est avant toute chose, I'Être infini; il ne saurait donc être considéré ni comme l'ensemble des êtres, ni comme la somme de ses propres attributs. $M$ ais sans ces attributs et les effets que en résultent, c'est-à-dire sans une forme déterminée, il est à jamais impossible ou de le comprendre ou de le connaître. Ce principe est assez clairement énoncé lors-qu'on dit 'qu'avant la création D ieu était sans forme, ne ressemblant à rien, et que, dans cet état, aucune intelligence ne peut le concevoir'." H istoire des doctrines ésoteriques, París, Payot, 1940, p. I28. 
y forma absoluta del universo equival ente del concepto abstracto, de la idea, es decir, del logos o del verbo.9 Partiendo de esto, Gorostiza investiga en su poema la forma y la sustancia intelectiva humana y divina. No se puede excluir la idea de ver en esto y, en particular, en la metáfora del vaso de agua, una influencia de los escritos de Abraham Abulafia. Gershom Scholem resume las ideas de éste de la manera siguiente:

Es el meta de Abulafia - tal como él mismo lo expresa-, "descerrajar el alma, desanudarla de sus ataduras" [... ] ¿Q ué significa tal símbolo en el lenguaje de Abulafia? Él afirma la existencia de ciertas paredes que separan la vida individual del alma humana de la corriente cósmica de la vida, la cual fluye por toda la creación personificada para él en el intellectus agens de la filosofía medieval. Existe un dique, que reduce al alma al ámbito natural de la vida humana y evita que la arrastre la corriente de lo divino que fluye al rededor y bajo ella. El mismo dique impide también al alma participar cognitivamente de lo divino. Los "sellos" impresos al alma evitan tal anegamiento y aseguran su función natural. ${ }^{\text {Io }}$

La dicotomía forma-sustancia es una constante en la obra de Gorostiza, ya localizable en sus primeros poemas como, por ejemplo, al inicio de la segunda de sus $C$ anciones para cantar en las barcas:

\author{
No ES agua ni arena \\ la orilla del mar. \\ El agua sonora \\ de espuma sencilla \\ el agua no puede \\ formarse la orilla.
}

9. Explica M arquès-Rivière: "Ainsi, ce qu'on appelle l'homme céleste ou la première manifestation divine n'est pas autre chose que la forme absolue de tout ce qui est; la source de toutes les autres formes, ou plutôt de toutes les idées; en un mot, la pensée suprême, la même qui ailleurs est appelée le logos ou le Verbe." I bidem, p. iso.

Io. Gershom Scholem, Die jüdische M ystik in ihren $\mathrm{H}$ auptströmungen, Frankfurt del M ain, Suhrkamp Taschenbuch W issenschaft, 1980, p. I42 [t.d.a.]. 
DOI: http://dx.doi.org/10.22201/iie.18703062e.2000.77.1943

196 ALBERTO PÉREZ-AMADOR ADAM

M as tal dicotomía tan sólo alcanzará sus últimas consecuencias en M uerte sin fin por medio de la metáfora del vaso de agua:

N o obstante - oh paradoja - constreñida

por el rigor del vaso que la aclara,

el agua toma forma.

$(1,20-22)$

Considero el origen de tal metáfora en un fragmento de Primero sueño. Ahí, sor Juana expresa la sorpresa del alma ante la diversidad del cosmos, y describe sus vanos intentos de aprehender tal diversidad en un concepto con los siguientes versos:

permitiéndole apenas de un concepto confuso el informe embrión que, mal formado, inordinado caos retrataba de confusas especies que abrazaba

- sin orden avenidas, sin orden separadas, que cuanto más se implican combinadas tanto más se disuelven desunidas, de diversidad llenas- ,

ciñiendo con violencia lo difuso de objeto tanto, a tan pequeño vaso (aun al más bajo, aun al menor, escaso). ${ }^{\text {II }}$

Tal metáfora la desarrolla Gorostiza en las oposiciones ser humano-dios, vida-muerte, ilusión-realidad, significante-significado, Ienguaje-poesía, hasta

II. Cito por mi edición: El precipicio de Faetón. N ueva edición, estudio filológico y comento de Primero sueño de sor Juana I nés de la Cruz, Frankfurt/M adrid, Vervuert, 1996. Sor Juana encuentra la idea en la sentencia de T omás de Aquino, Q uidquid recipitur, ad modum recipientis recipitur. T ambién emplea la idea en los versos io5-ı08 de su último e inconcluso romance titulado "¿C uánto, N úmenes divinos... ?": "T odo lo que se recibe / no es mensura al tamaño / que en sí tiene, sino al modo / que es del recipiente vaso [... ]" 
rayar las ideas arriba explicadas de origen bíblico-gnóstico de la creación del universo opuestas al proceso creativo de la poesía. Pero Gorostiza realiza aún un paso más diferenciando la dicotomía forma-sustancia en cada uno de los elementos de las dicotomías arriba señaladas tanto en relación con su forma, como también en relación con su contenido. ${ }^{12}$ Gorostiza reconoce, al fin, que la forma (entiéndase Dios) determina al universo, al ser humano y al lenguaje en la medida que tal forma contenga la sustancia: ni la forma ni la sustancia son independientes una de otra, sino son tan sólo en la medida en que sacrifican la propia existencia por efecto del opuesto concediéndose en forma mutua la existencia:

$$
\begin{aligned}
& \text { El vaso de agua es el momento justo } \\
& \text { (VIII, 46) }
\end{aligned}
$$

La consecuencia no es la subordinación de la creación a su creador, sino la inversión de esta idea con resultados que rozan las esferas del pensamiento existencialista:

M ás amor que sed; más que amor, idolatría, dispersión de criatura estupefacta ante el fulgor que blande

- germen del trueno olímpico- la forma en sus netos contornos fascinados.

[...]

Ya puede estar de pie frente a las cosas.

Ya es, ella también, aunque por arte de estas limpias metáforas cruzadas un encendido vaso de figuras. (VI, II-I5, 38-4I)

Tal inversión influye la relación entre las oposiciones antes mencionadas hasta alcanzar los límites de la reflexión lingüística, es decir, los límites entre significado y significante.

I2. Esto sucede en forma análoga a las ideas luego desarrolladas por L ouis H jelmslev. Como ejemplo del desarrollo de las ideas correspondientes a forma y sustancia en relación con los correspondientes conceptos del tiempo, cfr. los versos 32-66 de la segunda parte del poema. 
La obra inicia comparando la divinidad con un vaso inasible que contiene al ser humano hasta en sus formas más insignificantes. La decisión de Gorostiza de contravenir las reglas gramaticales de la lengua castellana y escribir algunas voces con mayúscula tiene la finalidad de otorgarles una significación singular. En el segundo verso escribe la voz "dios" con minúscula mientras que la voz "diablo", con excepción de su mención en el último verso, se registra siempre con mayúscula. Con ello Gorostiza detiene la lectura atenta para invitar a reflexionar sobre el dios - con minúscula—, del cual dice que es:

\section{mentido acaso \\ por su radiante atmósfera de luces \\ $(1,3-4)$}

Esta imagen hallará su constatación al final de la obra en la metáfora de la estrella extinta $(x, 37-42)$ ya anunciada en forma parcial en los citados versos.

El ser humano es descrito por medio de tres imágenes que remiten a los elementos agua, tierra y aire. Esto alude a un tópico común de la literatura del Siglo de O ro, el cual, a su vez, tiene su origen en N icolás de Cusa (De docta ignorantia, I, III, C. 3). Ahí, el ser humano es descrito cual cifra del microcosmos, misteriosa sigla que reúne en sí estos tres elementos. Con la repetición fragmentaria del primer verso completa el octavo verso la introducción del poema. En estos iniciales ocho versos se encuentra, en forma directa 0 connotativa, la mayoría de los elementos de la segunda isotopía indicada. Al final de un fragmento de doce versos, donde el yo poético se identifica con el agua y el movimiento, surge el motivo del vaso de agua. Éste se relacionará, en los restantes versos, con los conceptos de las demás isotopías. Tales versos restantes $(1,20-49)$ se dividen en dos secciones donde se reflexiona sobre el agua en el vaso y sobre el vaso mismo. Entre los motivos presentados llama el interés la mención de la estrella $(1,39-40)$. Al inicio del poema, Dios fue igualado con una estrella, mas aquí la estrella es presentada como metáfora para designar al vaso. De tal manera, las dos menciones se presentan como las premisas de un silogismo que permite a Gorostiza deducir, al inicio de la segunda parte, la metáfora donde dios es igualado al vaso. Tales estructuras lógicas se repiten a lo largo de toda la obra, sumando dificultades al lector al sustituirse, en no pocos casos, los conceptos de sus términos por imágenes y metáforas. 
La segunda parte del poema se relaciona con la primera por la repetición del verso 38 seguido por la conclusión del silogismo mencionado, donde el vaso (la forma) es un símil para dios, y el agua (la sustancia) signa al ser humano:

Tal vez esta oquedad que nos estrecha

en islas de monólogos sin eco,

aunque se llama Dios,

no sea sino un vaso

que nos amolda el alma perdidiza,

$(I 1,2-6)$

Poco después Dios es identificado como el vaso que otorga la forma y nos crea a su imagen y semejanza

y nos pone su máscara grandiosa,

ay, tan perfecta,

que no difiere un rasgo de nosotros.

$(11,64-66)$

Pero no solamente se identifica a D ios con el vaso, sino también con el tiempo. Y aún más: el vaso que otorga la forma está compuesto de la sustancia del tiempo. Con esto se llega a la idea de considerar el tiempo como la esencia de $D$ ios y consiguientemente que el tiempo es el creador de todo.

La tercera parte inicia mencionando a Francisco de Asís, el cual interpreta la diversidad de formas surgidas durante la creación como un himno a Dios. Él representa la fe incondicional que no cuestiona y queda satisfecha en la contemplación de lo creado sin intentar la develación de sus misterios. La vida se desarrolla, para él, entre una perdida edad paradisiaca y una recompensa prometida por su fe ciega:

en esta aguda ingenuidad del ánimo

que se pone a soñar a pleno sol

y sueña los pretéritos de moho,

la antigua rosa ausente

y el prometido fruto de mañana 
DOI: http://dx.doi.org/10.22201/iie.18703062e.2000.77.1943

200

ALBERTO PÉREZ-AMADOR ADAM

Tal infantil fe ciega no reconoce la existencia de algo anónimo e inexplicable interpuesto entre él y su creador:

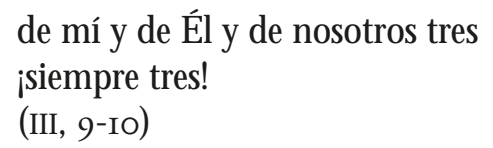

La identidad de aquella tercera persona permanecerá, al inicio, en la oscuridad y no será revelada hasta la cuarta parte del poema. Entretanto, la fe ciega identifica la creación con un artificioso acto de prestidigitación que, cual las cintas de colores extraídas del cilindro del mago, origina el surgimiento del universo con un único sonido similar al del corcho de una botella:

¡hop!

$(I I I, 26)$

Aquí observamos en acción la fuerza creadora de la forma. ${ }^{13}$ Pero, en oposición a lo referido en el Génesis, tal acto comprende también la creación del sufrimiento de manera que el creador, al observar a su criatura:

\section{[... ] no elude seguirla a sus infiernos,}

D e tal manera Gorostiza llega al problema filosófico fundamental de los gnósticos que preguntan cómo pudo el omnipotente creador realizar su obra de manera tan imperfecta permitiendo la existencia del dolor y el sufrimiento. La única respuesta plausible es aceptar que no fue D ios sino el demonio (entiéndase el demiurgo) quien completó la obra. Recuérdese la inversión de valores propuesta por los gnósticos con respecto a la cultura judeo-cristiana: para los gnósticos dios es aquél a quien en la cultura judeo-cristiana se llama demonio

I3. Explica M arquès-Rivière: "Abraham ben D aoud escribe en su comentario del Sefer Yetzirá: 'L orsqu'on affirme que les choses ont été tirées du néant, on ne veut pas parler due néant proprement dit; car jamais un être ne peut venir de non-être. M ais on entend par le non-être ce qu'on ne conçoit ni par sa cause, ni par son essence; c'est, en un mot, la cause des causes; c'est elle que nous appelons le non-être primitif, parce qu'elle est antérieure à l'univers: et après là nous n'entendons pas seulement les objets matériels, mais aussi la sagesse sur laquelle le monde a été fondé'." Op. cit., p. IзI. 
porque destruye esta creación tan imperfecta. En la cuarta parte de su poema, Gorostiza real iza la diferenciación entre dos fuerzas. La primera es aquella

\section{[... ] Inteligencia, soledad en Ilamas, que todo lo concibe sin crearlo!}

Como he señalado, es éste un fragmento clave para iluminar el trasfondo filosófico de la obra. Aquí se realiza una clara diferenciación entre la divina inteligencia que concibe y la fuerza realizadora de tales conceptos. La inteligencia divina es descrita sin vida ("páramo", v. i6; "helada" y "pétrea", v. I7; "sellada", v. 19; "cerrada", v. 2I) y atemporal ("tiempo paralítico", v. i8). Esto es interesante si se recuerda que antes descubrió la sustancia de Dios en el tiempo. Sin crear nada, tal inteligencia concibe al ser humano, el dolor y el lenguaje de manera como se describe en el segundo epígrafe (Proverbios 8, 3o) que antecede la obra:

[... ] y fui su delicia todos los días, teniendo solaz delante de él en todo tiempo.

Ella concibe, pero no crea. Es la unidad perfecta (IV, 34) del amorfo continuo, sin intervención de la forma, es decir, del demiurgo. Es ella la misteriosa persona citada en la tercera parte del poema, la cual, junto con Dios, constituye una misteriosa unidad de tres personas:

$$
\begin{aligned}
& \text { con Él, conmigo, con nosotros tres; } \\
& \text { como el vaso y el agua, sólo una } \\
& \text { (IV , 42-43) }
\end{aligned}
$$

$M$ as, al final, después de haber concebido todo, tal inteligencia no pronuncia el Verbo creador (Juan I, I), quedándose

$$
\begin{aligned}
& \text { en la orilla letal de la palabra } \\
& \text { y en la inminencia misma de la sangre } \\
& \left(\text { IV }, 45^{-46)}\right.
\end{aligned}
$$

La razón de esto radica en el hecho de ser ella sólo origen conceptual, mientras la fuerza creadora de la forma (entiéndase el demiurgo) realiza tales conceptos, pronunciando la palabra correspondiente. La idea es continuada 
DOI: http://dx.doi.org/10.22201/iie.18703062e.2000.77.1943

202

ALBERTO PÉREZ-AMADOR ADAM

cuando G orostiza equipara en diferentes partes de su obra la creación del universo con la creación poética quedando igualados el poeta y su obra poé tica al demiurgo y su creación demoniaca.

D espués de las largas y complejas estructuras de los versos anteriores la quinta parte resulta, en una primera impresión, una escisión con el resto de la obra. El autor utiliza otra medida, la de la seguidilla (penta y heptasílabos). Pero su sencillez es engañosa. Esta parte se constituye de tres incisos de tres cuartetas cada uno. C ada inciso describe la participación del agua en alguno de los tres reinos de la naturaleza y está separado del siguiente inciso por dos versos que mencionan la falta de olor, color y gusto del líquido.

En la escolástica se consideraba que el ser humano cifraba en su ser el reino mineral, vegetal y animal, siendo el eslabón entre estos tres reinos de la natural eza que, además, gracias a la acción de su alma inmortal, comunicaba aquellos reinos con las regiones celestes. ${ }^{I 4} \mathrm{M}$ as con $\mathrm{G}$ orostiza no es el ser humano quien une aquellos tres reinos, sino el agua. En realidad, después de concebida la creación (parte Iv) y consumada su realización material, provocada por la forma, al dividir el amorfo continuo (parte III), se presenta la sustancia que alcanza su máxima diferenciación en las distintas especies de los diversos reinos de la naturaleza:

¡Yo, el heliotropo, yo!
¿Yo? El jazmín.

Tal máxima diferenciación de la creación provoca que el alma no pueda reconocer a D ios. Scholem, al exponer las ideas de Abulafia, explica este conflicto del alma (entiéndase con G orostiza del agua):

Puesto que el alma percibe los burdos objetos de la naturaleza y aprehende sus formas, se constituye de ello, su función natural, una singular vida anímica, a la cual le han sido colocados los sellos de lo finito. La vida normal del alma se circunscribe a los límites impuestos por los afectos sensoriales y las percepciones. $M$ as, si el alma se colma de tales formas y afectos, se vuelve extremadamente

I4. G regorio M agno, H omilía 29 sobre los Evangelios (sobre san M arco, XVI): "O mnis creatura aliquid habet homo. $\mathrm{H}$ abet namque commune esse cum lapidibus, vivere cum arboribus, intelligere cum angelis [... ] Juxta aliquid, omnis creatura esto homo." 
difícil pasar de ahí a la contemplación de las cosas divinas y las formas espirituales puras. ${ }^{15}$

Al término del último inciso de la quinta parte del poema, Gorostiza cita en forma velada un dicho mexicano: "Q uien por su gusto se muere, hasta la muerte le sabe." Tal se ha empleado cuando al guien, con plena conciencia de las inevitables malas consecuencias de sus actos, los cumple. El sentido de la cita se resuelve considerando que, para G orostiza, el centro del microcosmos lo representa el agua, de la manera como para los escolásticos lo era el ser humano, fungiendo como bisagra engarzadora que une todas las esferas y que, conservando y reproduciendo la vida, mantiene, en última consecuencia, también la muerte.

La quinta parte concluye con una cuarteta titulada, entre corchetes, "BaiIe". N uevamente G orostiza cita un dicho que implica la metáfora fundamental del poema: "ahogarse en un vaso de agua". Tal dicho es empleado cuando alguien se desespera ante exiguas razones. En un primer instante parece como si su calidad inodora, incolora e insípida arrastrase al agua a la desesperación. Pero, considerando la metáfora fundamental del poema, a saber el vaso de agua, para designar a dios y al hombre, entiéndase la forma y la sustancia, en conjunción con el arriba mencionado morir incesante, sustentado en su existir por el agua, esta cuarteta pierde su tono infantil alcanzando un carácter existencial.

A partir de la sexta parte se inicia en el poema una nueva sección. Las partes sexta, séptima y octava deben ser consideradas en forma conjunta. Se dedican éstas, respectivamente, al estudio de la sustancia, el vaso de agua y la forma. El agua, entiéndase la sustancia, exige la forma para poder actuar en el mundo material:

quiere, además, oírse.

[... ]

quiere, además, un tálamo de sombra,

un ojo,

para mirar el ojo que la mira.

(vI, 19, 23-25)

I5. Scholem, ibidem, I43 [t.d.a.]. 
Ya he explicado que la forma no es, en el pensamiento gnóstico, un producto de $D$ ios sino del demiurgo. Por consecuencia, resulta la veneración de la creación una idolatría. Aquella división del amorfo continuo, necesaria para el surgimiento de la creación y ocasionada por la acción de la forma abstracta, es considerada ahora un enlace diabólico (VI, 29). La creación misma es interpretada como un engaño, como una alucinación condenada de manera ineludible, después de incontables tormentos, a la destrucción (vI, 42-49).

Pero de la manera como aquí la sustancia languidece por la forma, en la parte vII se describe cómo ésta aspira al canzar a aquélla. Sin la sustancia, la forma no tiene sentido. M as la unión de ambas ocasiona la pérdida de los atributos esenciales de la forma en el instante mismo de asumir los naturales al líquido:

se ablanda, se adelgaza;

ya su sobrio dibujo se le nubla,

ya, embozado en el giro de un reflejo,

en un llanto de luces se liquida.

(VII, 22-25)

En esta parte, la forma abstracta es adorada hasta su faraónica entronización, nombrándosele con epítetos proparoxítonos. Tales, en la lengua castellana, suenan altisonantes y son empleados con frecuencia por los poetas modernistas como consecuencia de su particular interés por la forma poética. M as la forma contiene en sí el germen de la destrucción revelándose como una no diuturna ilusión.
El vaso de agua es el momento justo.
En su audaz evasión se transfigura, tuerce la órbita de su destino
y se arrastra en secreto hacia lo informe. (VIII, 46-49)

La novena, la más larga parte del poema, está constituida de siete incisos. LoS últimos seis incisos desarrollan los motivos propuestos en el primero. Éste, a su vez, se compone de tres segmentos. Los primeros recapitulan los motivos principales de las partes VI, VII y VIII: la sustancia pierde su característica original en la forma de manera análoga a como ésta pierde la propia al contacto 
DOI: http://dx.doi.org/10.22201/iie.18703062e.2000.77.1943

con aquélla. Pero, durante el instante mínimo de tal suceso, se da la posibilidad de hacer retroactiva la división del amorfo continuo, provocada por la acción de la forma, hasta recuperar la unidad original. ${ }^{16}$ Los siguientes seis incisos, que inician todos con la palabra "porque", describen tal único "perpetuo instante del quebranto" "en que los seres todos se repliegan" (IX, I9, 24). En el primer inciso desaparecen el lenguaje, la naturaleza y el deseo. La breve mención de la desaparición del lenguaje será recapitulada, como motivo principal, en el segundo inciso. Esto se explica no sólo porque el lenguaje, por principio de cuentas, alaba la forma y le sirve de instrumento al poeta para la creación de otro (poético) mundo de formas, sino porque ella misma es una forma (significante) que encierra una sustancia (significado). ${ }^{17}$

Los tres siguientes incisos (IX, 92-129, I30-163, I64-I9I) describen la involución en el perpetuo instante del quebranto $(1 \mathrm{X}, 19,94)$ de todos los seres de los tres reinos de la naturaleza (animales, plantas y minerales) ${ }^{18}$ hasta su origen para, finalmente, "constituir el escenario de la nada" (IX, 26, 219-224). El final es una paráfrasis del inicio del Génesis: al término de la completa involución vuelve a flotar el espíritu de D ios sobre las grandes aguas. Su verbo ya no es creativo, sino tan sólo un

$$
\begin{aligned}
& {[\ldots] \text { ] llanto más Ilanto aún que el Ilanto }} \\
& (I X, 227)
\end{aligned}
$$

La diferencia fundamental entre ésta y la escena bíblica radica en la vulnerabilidad de Dios y toda su obra (IX, 228). Las partes Ix y IV dan término a las

I6. Explica M arquès-Rivière: "Le Zohar ajout à ce sujet: 'T outes les choses dont ce monde est composé, l'esprit aussi bien que le corps, rentreront dans le principe et dans la racine dont elles sont sorties. II est le commencement et la fin de tous les degrés de la création; tous ces degrés sont marqués de son sceau, et on ne peut le nommer autrement que par l'unité; il est l'être unique, malgré les formes innombrables dont il est revêtu'." O p. cit., p. I3I.

17. Explica M arquès-Rivière: "Avec les vingt-deux lettres, en leur donnant une forme et une figure, en les mêlant et les combinant de diverses manières, Dieu a fait l'âme de tout ce qui est formé et de tout ce qui le sera. C'est sur ces mêmes lettres que le Saint, béni soit-il, a fondé son nom sublime et ineffable [... ] Ainsi, la forme matérielle de l'intelligence, représentée par les vingt-deux lettres de l'alphabet, est en même temps la forme de tout ce qui est [... .]." I bidem, pp. I46-I47.

I8. La idea de la vida y de las posibilidades de evolución de los minerales se origina en el Kybalion del Corpus $\mathrm{H}$ ermeticum y fue ampliamente empleado en la alquimia y en el pensamiento rosacruz del renacimiento tardío. 
DOI: http://dx.doi.org/10.22201/iie.18703062e.2000.77.1943

206

ALBERTO PÉREZ-AMADOR ADAM

dos grandes secciones del poema. Ambas partes tratan de la divinidad en el sentido gnóstico. La cuarta parte describe aquella fuerza que concibe, pero no crea: la Inteligencia que no se atreve a pronunciar el verbo creador:

que reconcentra su silencio blanco

en la orilla letal de la palabra

y en la inminencia misma de la sangre.

(IV, 44-46)

La novena parte, retomando algunas imágenes de la Biblia, ${ }^{19}$ trata tanto de la fuerza que crea, pero no concibe, como también de la involución de la creación. Tal fuerza, como lo sabemos de Juan (I, I), pronunció el Verbo que tuvo como consecuencia la creación y, por consiguiente, el dolor y la muerte. Pero aquí nos enteramos de que tal trasgresión es el origen de la muerte de tal fuerza:

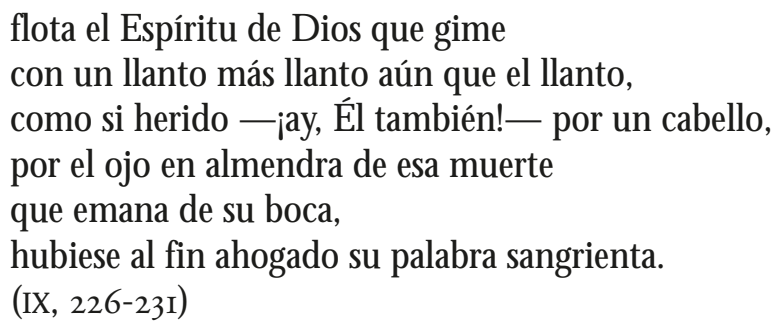

Esta novena parte termina con las palabras "iALELUYA, ALELUYA!" como si fuesen un canto a la nada. La décima sección del poema es de simulada facilidad por la forma menor empleada. Aquí se utiliza el romance (octosílabos rimados) repartido en tres estrofas. $Y$, como también sucedió en la quinta parte, ésta cierra con un inciso, aquí de seis versos, titulado en corchetes [Baile]. Cada una de las tres estrofas indaga la naturaleza del demonio iniciando con una cita de una canción infantil, donde se imita al diablo tocando a la puerta del cuarto de los niños. La primera estrofa repite la idea de la destrucción de dios, del amorfo continuo, por el efecto divisor de la forma.

19. Principalmente se localizan motivos del Apocalipsis de san Juan. 0 tros pasajes recuerdan fragmentos de Juan $(1, \mathrm{I})$, de los Proverbios $(3,6)$, del Levítico (I7, II) y del Deuteronomio (I2, 23). 
La segunda describe el gozo sensorial ofrecido por la forma. La tercera acusa al demonio y, por consecuencia, a la creación, de la muerte de la divinidad: D ios no es otra cosa que una estrella remotamente extinta, cuya luz aún observamos, a pesar de haber dejado de existir hace mucho tiempo. La metáfora remite al lector al inicio de la obra $(1,2-3)$ donde se le aludió, revelándose la estructura cíclica de la obra.

La idea de la muerte de dios fue un problema común en el llamado Siglo de 0 ro de la literatura sefardí en la España del siglo xIII. Scholem resume la larga argumentación dada por Maimónides en su Guía de los perplejos de la manera siguiente:

¿Cómo puede afirmarse que dios vive? ¿No es tal una reducción de la infinita variedad de su ser? Consecuentemente, la oración "D ios vive" sólo puede significar que no está muerto, es decir, que es lo contrario de todo lo negativo. Es la negación de la negación. ${ }^{20}$

La mística española no halló solución para el problema de la muerte de D ios hasta que fueron retomadas las ideas gnósticas de la doble natural eza divina, es decir, del dios en sus formas y del deus absconditus. Como he señalado antes, tales ideas también se localizan en G orostiza. La diferencia entre aquellos filósofos y G orostiza es que, para él, el problema reside no en la muerte del dios creador, es decir del demiurgo, sino justamente en la muerte de aquella fuerza que concibe. Esto, en su última consecuencia, le niega a la humanidad la posibilidad de redención de la desgracia.

Y para restarle al ser humano el último vestigio de esperanza, en los seis versos finales, Gorostiza le niega, aun al poeta, por causa del insomnio, la creación de un mundo onírico restándole sólo la muerte: la muerte es descrita como una putilla dado que, sin distinción, irá tarde o temprano con todos los seres humanos.

D entro de la tradición gnóstica, Gorostiza sabe que la forma debe involucionar hasta la restauración de la sustancia absoluta (¿dios?, ¿la poesía?) dando término al creativo acto (¿de la Shejiná?, ¿del demiurgo gnóstico?, ¿del poeta?) de división de la sustancia. Dicho acto 
[... ] sueña que su sueño se repite, irresponsable, eterno, muerte sin fin de una obstinada muerte (III, IIO-II2)

Gorostiza constata la afirmación de sor Juana de la humana imposibilidad de lograr la aprehensión cognitiva al proponer como tema el incontenible cambio y la eterna repetición de las apariciones fenomenológicas. Continuando la temprana crítica de sor Juana al racionalismo, Gorostiza formula una crítica a la modernidad análoga a la propuesta por N ietzsche. Pero, si bien G orostiza conocía las ideas de $\mathrm{N}$ ietzsche, aquí debe pensarse menos en la idea del eterno retorno que en las ideas gnósticas, arriba expuestas, de la eterna división de la sustancia divina por la infausta acción del demiurgo.

En el marco de la crítica a la modernidad, propuesta por N ietzsche, G orostiza retoma otro tema: el motivo de la palabra creadora, del logos divino que contiene en potencia toda la creación. Ya la gnosis, el Evangelio de san Juan y la Cábala conocían esta idea. El idioma, el problema de la estructura que éste le impone al proceso cognoscitivo - reconocido al mismo tiempo por W ittgenstein en el Tractatus-, las fronteras intelectivas del idioma y las fronteras lingüísticas del conocimiento son todos problemas centrales en la obra de Gorostiza. El mérito de Gorostiza reside en haber continuado la crítica al proceso cognoscitivo propuesto por sor Juana y haber recuperado para la crítica al discurso de la modernidad, centrada en el logos, la experiencia hermenéutica de la filosofía sefardí del siglo xIII español.

Gorostiza y Cuesta aplicaron una radical crítica a los principios racionales que suplantan el poder unificador de la religión. En la obra de Cuesta, particularmente en Canto a un dios mineral, se da, a partir de una ontologización del lenguaje, una nueva respuesta al problema de la crítica al proceso cognoscitivo. Cuesta confirma la cognición y supera el existencialismo de Gorostiza con ayuda de las teorías platónicas del conocimiento, descubriendo la posibilidad cognitiva por medio de la percepción metafísica del logos absoluto. Para ello parte de los principios propuestos por H eráclito y Parménides de la mutabilidad de la naturaleza y el orden del universo. Entre ambas posiciones, entre sor Juana y Jorge Cuesta se encuentra, no solamente desde el punto de vista cronológico, sino también filosófico, José Gorostiza. Tres años antes del Canto a un dios mineral, Gorostiza reflexiona, partiendo de forma y contenido, sobre el logos, y rechaza todo intento de comprenderlo al 
descubrir la mutua dependencia de la sustancia y de la forma, su constante cambio y la inevitable repetición de su destrucción. N o sólo reconoce, como $\mathrm{N}$ ietzsche, la muerte de Dios, sino sabe que, por efecto del eternamente repetitivo acto creador del demiurgo, el amorfo continuo fue asesinado hace mucho tiempo y aquello que suponemos que es dios resulta tan sólo la reverberación de una estrella ya extinta $(x, 29-42)$. Así, para G orostiza, toda la realidad es una disolución de la unidad original. En oposición a las ideas de $\mathrm{N}$ ietzsche, que intentó restablecer tal unidad por medio de una mitología estetizada, para Gorostiza la única vía de restaurarla es a partir de la total disolución de la creación. Tal proceso de involución ontológica, dirigido a la restauración del amorfo continuo y descrito en la novena parte, indica que la tan anhelada respuesta a las preguntas fundamentales se encuentra sólo en la muerte.

La obra de G orostiza, tal como la de Cuesta, expresa un profundo deseo de superar los límites impuestos del lenguaje: ambos poetas tienen su origen en el pensamiento filosófico del siglo xx y están conscientes tanto de la dependencia mutua de nuestras estructuras intelectivas y la capacidad cognitiva de los sistemas del lenguaje, como también de la imposibilidad de la aprehensión del logos por la palabra.s 
DOI: http://dx.doi.org/10.22201/iie.18703062e.2000.77.1943

\section{Bibliografía}

Cohen, Esther, La palabra incondusa. Si ete ensayos sobre cábala, M éxico, U niversidad N acional Autónoma de M éxico, I99I.

Die Gnosis: Zeugnisse der Kirchväter, unter $M$ itwirkung von Ernst $\mathrm{H}$ aenchen und $\mathrm{M}$ artin Krause eingeleitet, übersetzt und erläutert von W erner Foerster, M unich / Zurich, Artemis \& W inkler, I995.

Die Gnosis. D er M anichäi smus, unter M itwirkunhg von J es Peter Asmussen eingeleitet, übersetzt und erläutert von Alexander Böhlig, M unich / Zurich, Artemis \& W inkler, I995.

D ie G nosis: Koptische und mandäische Q uellen, eingeleitet, übersetzt und erläutert von $M$ artin Krause und Kurt Rudolph, herausgegeben von W erner Foerster, M unich / Zurich, Artemis \& W inkler, I995.

Farandos, G eorgios D., D ie W ege des Suchens bei H eraklit und Parmenides, W ürzburg, Könighausen-N eumann, 1982.

Garza Cuarón, Beatriz, "Simetría y correspondencias en M uerte sin fin de José Gorostiza", en varios, D esindes literarios, M éxico, El Colegio de M éxico, 1977, pp. 83-94 (J ornadas, 82).

Gorostiza, José, Poesía, M éxico, Fondo de Cultura E conómica, ig64.

Endloser T od / M uerte sin fin, D eutsch-Spanisch, übersetzt von R. W ittkopf und L. Klünner. H rsg. von Alberto Pérez-Amador Adam, Aachen, Rimbaud, 1995.

Greimas, A. J., Sémi otique. D ictionnaire rai sonné de la théorie du langage, París, H achette-U niversité, I979.

H abermas, Jürgen, Der philosophische Diskurs der M oderne. Zwölf Vorlesungen, Frankfurt, Suhrkamp, 1993.

Lacarrière, J., Los gnósticos, M éxico, La Red de J onás, I982.

Leisegang, $\mathrm{H}$ ans, D ie G nosis, Stuttgart, Alfred K röner Verlag, 1985.

Lennep, J. van, Artey alquimia, trad. Antonio Pérez, M adrid, N acional, I978.

Lyotard, J ean-François, La condition postmoderne, París, Éditions de M inuit, 1979.

$M$ arquès-Rivière, J ean, $\mathrm{H}$ istoi re des doctrines ésotériques, París, Payot, I940.

O rtega M uñoz, Juan Fernando, Introducción al pensamiento de M aría Zambrano, M éxico, Fondo de Cultura Económica, 1994.

Paz, O ctavio, Sor J uana Inés de la Cruz o las trampas de la fe, Barcelona, Seix Barral, I982.

Pérez-Amador Adam, Alberto, El precipicio de Faetón. N ueva edición, estudio filológico e ilus tración al Primero sueño de sor J uana Inés de la Cruz, Frankfurt/M adrid, V ervuert, 1996.

, La sumisión a lo imaginario. N ueva edición, estudio y comento de C anto a un dios mineral de J orge Cuesta, Frankfurt/M adrid, V ervuert, 200 .

Scholem, G ershom, D iejüdische M ystik in ihren H auptströmungen, Frankfurt, Suhrkamp T aschenbuch, 1980 .

Zambrano, M aría, O bras reunidas, M adrid, Aguilar, I97I. 